\title{
Capacitação do Médico para Comunicar Más Notícias à Criança
}

\author{
Enabling Physicians to Communicate Bad \\ News to Children
}

Gimol Benzaquen Perosa ${ }^{I}$ Priscila Moreci Ranzani ${ }^{I}$

\section{PALAVRAS-CHAVE: \\ - Comunicação; \\ - Relações médico-paciente; \\ - Educação médica; \\ - Criança hospitalizada.}

\section{KEY WORDS:}

- Communication;

- Doctor-patient relation;

- Education, medical;

- Child, hospitalized.

Recebido em: 14/02/2007

Reencaminhado em: 06/02/2008

Aprovado em: 14/03/2008
468 REVISTA BRASLLEIRA DE EDUCAÇ̄̃o MÉDICA 


\section{INTRODUÇÃO}

Apesar de a morte ser uma constante no trabalho dos profissionais da saúde, essa problemática é pouco explorada nos currículos de Medicina e de Enfermagem, o que ocasiona uma abordagem inadequada e aumenta desnecessariamente o sofrimento do médico e do paciente, em especial daqueles sem expectativa de cura ${ }^{1}$.

No que toca à comunicação de más noticias, uma revisão de literatura² ${ }^{2}$ encomendada pela OMS nos anos 1990 mostrou que a preocupação maior dos pesquisadores está centrada na importância (ou não) de informar o paciente o quanto ele deve saber, mas que pouca atenção tem sido dada à capacitação do médico para enfrentar essas situações. $\mathrm{O}$ estudo detectou que os médicos assumem três posturas com relação a quanto informar: uns defendem que a informação tem que ser dada sempre, na íntegra, independentemente das percepções ou necessidades individuais do paciente; outros pregam exatamente o contrário: em nenhuma circunstância os pacientes devem ser informados de doença letal, e o profissional deve lançar mão de mentiras e enganos para garantir a adesão ao possível tratamento; a terceira visão, uma abordagem mais flexível, recomenda levar em conta fatores psicológicos e sociológicos, mas os profissionais que defendem essa tendência esclarecem pouco como respeitar a subjetividade e como se deve dar a notícia. Uma análise retrospectiva mostrou que cada uma dessas tendências representou o pensamento majoritário de determinada época. Se em trabalhos mais antigos, da década de 1960, a maioria dos médicos preferia não contar aos pacientes que eles tinham câncer, uma pesquisa realizada nos anos 1970 verificou que a maioria dos entrevistados se sentia na obrigação de dar toda a informação possível ${ }^{3}$.

Se essa questão ainda é muito debatida com relação a pacientes adultos, quando se trata da criança, o tópico é muito pouco abordado. Os manuais editados nos anos 1990 para facilitar a comunicação de más noticias nos serviços de emergência pouca referência fazem a pacientes pediátricos, e, mesmo nesses casos, a maior preocupação está em como informar os pais. Assim, Greenberg et al. ${ }^{4}$ se propuseram a habilitar alunos a notificar, da melhor forma possível, pais de crianças que haviam ido a óbito devido a acidente de carro ou bebês trazidos à emergência por morte súbita. Em outra pesquisa, Krahn, Hallum e Kime ${ }^{5}$ entrevistaram pais de bebês que haviam recebido diagnóstico de atraso do desenvolvimento associado a etiologias diversas para saber que estratégia os pais consideravam a forma mais adequada para receber essa notícia.

A comunicação direta com a criança não é usual nos atendimentos pediátricos. Mesmo em consultas de rotina, de pouca gravidade, a criança tem tido uma participação bastante peque- na. Os médicos pedem às crianças que descrevam os sintomas, mas tendem a excluí-las das informações referentes a diagnóstico e tratamento. $\mathrm{O}$ médico se dirige principalmente aos pais, possivelmente pela dificuldade de abordar diretamente as crianças pequenas ou guiado pela crença de que elas podem não compreender as explicações, assustar-se e sofrer perturbações emocionais. Não revelar informações seria uma forma de protegê-las ${ }^{6}$.

Atualmente, várias pesquisas demonstram que, desde idade muito precoce, as crianças compreendem as informações médicas. Segundo achados recentes, a aquisição dos conceitos de saúde e doença se inicia quando a criança tem de quatro a seis anos, e a compreensão da etiologia, prevenção e cura das doenças vai amadurecendo como conseqüência do aumento da idade e da experiência ${ }^{7,8,9}$. Comprovou-se, inclusive, que a comunicação direta entre o profissional e a criança, principalmente quando ela é portadora de quadros crônicos, contribui para melhorar a adesão ao tratamento, satisfação com o atendimento, e uma conseqüente melhora do prognóstico ${ }^{10,11}$.

Possivelmente a situação mais difícil e dramática para o médico ocorre quando o profissional tem que informar a uma criança que ela é portadora de quadro de prognóstico reservado ou de doenças em estágio terminal. Nesses momentos, os profissionais se deparam com diversas questões que não se restringem ao aspecto técnico-científico, mas adentram o campo da subjetividade e da ética. $\mathrm{O}$ assunto ainda é pouco abordado nas publicações, mas, nos poucos artigos encontrados, percebe-se que é uma questão polêmica e sem consenso.

Adotando uma posição radical, Nitscke $e t$ al. ${ }^{12}$ se propuseram a oferecer todas as informações possíveis a seus pacientes infantis com câncer em estágio terminal. Com o consentimento dos pais, crianças com mais de três anos eram informadas sobre o diagnóstico (câncer) e a possibilidade de morte caso não houvesse tratamento. Se este procedimento levantou várias polêmicas e desacordos, a maioria dos autores pareceu adotar uma posição mais conciliatória, apesar de reconhecer que, independentemente da idade, a honestidade era a melhor política frente à morte iminente. Em seus artigos, esses profissionais se posicionam a favor da escuta como a melhor conduta para avaliar que tipo de informação a criança quer naquele momento ${ }^{13,14,15}$.

Embora a maioria dos profissionais preconize que a criança tem que ser informada e consultada, um trabalho observacional, desenvolvido por Tates e Meeuwesen ${ }^{11}$, mostrou que, na prática, a atitude mais comum dos pediatras ainda é o silêncio ou o mascaramento da situação.

Para os educadores, a questão que se coloca em primeiro lugar é o que se entende, no contexto pediátrico, por uma má notícia. Se o trabalho de Nitscke et al. ${ }^{12}$ abordou pacientes terminais, há vários outros médicos que consideram más noticias 
contar à criança as limitações que doenças e tratamentos vão impor à sua rotina e a conseqüente perda de qualidade de vida. Por outro lado, urge saber como capacitar os futuros médicos a enfrentar essas situações difíceis: discutir as regras morais que estão por trás da decisão de contar ou não contar? Oferecer treinamento formal? Avaliar os aspectos subjetivos envolvidos e os sentimentos que essa situação desperta no próprio médico?

Dentro de uma reforma curricular que pretende contemplar uma visão humanista da relação médico-paciente, antes de planejar ações, este trabalho teve por objetivo resgatar, junto a profissionais de saúde que atendem crianças, o que consideram uma má notícia, a necessidade de transmiti-la à criança e como foram capacitados para essa função.

\section{MÉTODO}

Trata-se de um estudo transversal que se propôs a avaliar como a população de médicos de um hospital-escola que atendia crianças, em contextos diversos - ambulatório, pronto-socorro, enfermaria e UTI pediátrica - se posicionava quanto a comunicar à criança uma má noticia. Alguns sujeitos eram pediatras generalistas, e outros, médicos de especialidades. $\mathrm{O}$ estudo foi realizado após aprovação do Comitê de Ética em Pesquisa da FMB-Unesp.

Utilizou-se um questionário semi-estruturado, baseado em similar elaborado por $\mathrm{Oken}^{3}$, para médicos que atendiam pacientes adultos (Anexo). A primeira parte do questionário visava levantar um perfil sociodemográfico dos médicos. A segunda parte compreendia um conjunto de questões abertas e fechadas, que versavam sobre o conceito de má notícia para a criança, a necessidade de comunicá-la e, se em sua prática, o médico tinha que enfrentar essas situações. Interessava, principalmente, como o médico se capacitou para essa função: as oportunidades de discussão desse tema, os treinamentos específicos na educação formal e informal e os sentimentos que essa situação despertava.

Tabularam-se as informações relativas à caracterização dos sujeitos da amostra. Para analisar a questão aberta, a me- todologia utilizada foi a análise de conteúdo baseada no referencial de Bardin ${ }^{16}$. Tanto essas categorias quanto os diferentes tópicos do questionário foram quantificados em termos de freqüência, porcentagem e incidência, de acordo com a natureza da variável. Para interpretar os dados, as variáveis foram cruzadas e se aplicou o Teste Exato de Fisher, com nível de significância de 0,05 .

\section{RESULTADOS}

Dos 78 questionários distribuídos houve um retorno de $68 \%$, isto é, 53 médicos responderam ao questionário (25 médicos e 28 residentes). Grande parte dos médicos tinha de um a dez anos de formada (56,6\%), 11,3\% eram recém-formados (menos de um ano), 15,1\% estavam formados de 11 a 20 anos e 17\% tinham mais de 21 anos de formados.

Não houve uma forma única de definir a má notícia, mas a maioria da amostra $(57,14 \%)$ a definiu como "a necessidade de comunicar um diagnóstico ou prognóstico ruim”. Alguns médicos mais novos, com idade entre 22 e 29 anos, incluíram na definição o fato de a informação provocar algum tipo de conseqüência emocional à criança, enquanto $50 \%$ dos médicos mais velhos, com mais de 51 anos, acrescentaram a dificuldade de comunicar à criança que ela seria submetida a um procedimento doloroso. A maioria dos médicos $(76,2 \%)$ e dos residentes $(64,3 \%)$ já tinha vivenciado essa situação em sua prática profissional.

Com relação ao sentimento do médico ao dar a má noticia à criança, $43 \%$ referiram a tristeza como sentimento prevalente e $40 \%$ dos respondentes relataram ter a sensação de dever cumprido.

Apesar de a maioria dos sujeitos $(69,8 \%)$ ter relatado que não recebeu ensinamentos específicos em sua formação (Tabela 1), poucos referiram sentimentos de insegurança ou constrangimento ao enfrentarem a situação. Uma parcela de 83,3\% dos médicos formados há um ano, em oposição aos médicos formados há mais tempo, disse ter recebido, durante a graduação, ensinamentos específicos e treinamento para dar más notícias à criança.

TABELA 1

Número e porcentagem de sujeitos que relataram ter recebido instruções específicassobre como dar más notícias à criança, durante a graduação

\begin{tabular}{|c|c|c|c|c|c|c|c|c|c|c|}
\hline \multirow{2}{*}{$\begin{array}{l}\text { Instruções } \\
\text { específicas }\end{array}$} & \multicolumn{2}{|c|}{1 ano } & \multicolumn{2}{|c|}{1 a 10 anos } & \multicolumn{2}{|c|}{11 a 20 anos } & \multicolumn{2}{|c|}{21 a + de 30 anos } & \multicolumn{2}{|c|}{ Total } \\
\hline & $\mathbf{N}$ & $\%$ & $\mathbf{N}$ & $\%$ & $\mathbf{N}$ & $\%$ & $\mathbf{N}$ & $\%$ & $\mathbf{N}$ & $\%$ \\
\hline$S$ & 5 & 83,3 & 6 & 20,0 & 2 & 25,0 & 3 & 33,3 & 16 & 30,2 \\
\hline $\mathrm{N}$ & 1 & 16,7 & 24 & 80,0 & 6 & 75,0 & 6 & 66,7 & 37 & 69,8 \\
\hline $\mathrm{T}$ & 6 & 100,0 & 30 & 100,0 & 8 & 100,0 & 9 & 100,0 & 53 & 100,0 \\
\hline
\end{tabular}

$\mathrm{F}=0,03<0,05$ 
TABELA 2

Número e porcentagem de sujeitos que relataram ter discutido o tema comunicação de más notícias à criança, durante a graduação

\begin{tabular}{|c|c|c|c|c|c|c|c|c|c|c|}
\hline \multirow{2}{*}{$\begin{array}{c}\text { Tema discutido na } \\
\text { graduação }\end{array}$} & \multicolumn{2}{|c|}{1 ano } & \multicolumn{2}{|c|}{1 a 10 anos } & \multicolumn{2}{|c|}{11 a 20 anos } & \multicolumn{2}{|c|}{21 a 30 anos } & \multicolumn{2}{|c|}{ Total } \\
\hline & $\mathbf{N}$ & $\%$ & $\mathbf{N}$ & $\%$ & $\mathbf{N}$ & $\%$ & $\mathbf{N}$ & $\%$ & $\mathbf{N}$ & $\%$ \\
\hline$S$ & 6 & 100,0 & 15 & 50,0 & 2 & 25,0 & 3 & 20,0 & 26 & 48,1 \\
\hline $\mathrm{N}$ & 0 & 0 & 15 & 50,0 & 6 & 75,0 & 6 & 80,0 & 27 & 51,9 \\
\hline $\mathrm{T}$ & 6 & 100,0 & 30 & 100,0 & 8 & 100,0 & 9 & 100,0 & 53 & 100,0 \\
\hline
\end{tabular}

$\mathrm{F}=0,02<0,05$

Uma parcela maior de sujeitos $(48,1 \%)$ referiu ter discutido o tema durante a graduação ou residência (Tabela 2). Todos os recém-formados e $50 \%$ dos formados até dez anos atrás relataram ter discutido a comunicação de más notícias durante o curso, em oposição a 25\% dos médicos com mais de dez anos de formados e $20 \%$ dos sujeitos formados há mais tempo.

Todos os participantes da pesquisa consideraram importante contemplar tópicos referentes à comunicação de más notícias, inclusive a crianças, no currículo médico atual. Os sujeitos foram unânimes em afirmar que, antes de informar a criança, é preciso notificar os pais ou responsáveis. Com o consentimento destes, houve relatos diferentes de como atuar: enquanto $50 \%$ dos residentes disseram acreditar que a criança deve receber toda a informação, $70 \%$ dos médicos com mais experiência no serviço relataram que elas deveriam receber apenas uma parcela das informações.

\section{DISCUSSÃO}

A análise dos dados parece mostrar que a maioria dos profissionais reconheceu, de forma quase unânime, que a criança deve ser posta a par do seu estado de saúde e dos procedimentos aos quais vai ser submetida, mas ainda é polêmica a definição do que é uma má notícia e como a criança deve ser informada. A grande maioria da amostra pareceu optar por uma atitude cautelosa, informando primeiramente os pais, e, no caso dos médicos mais velhos, oferecendo à criança apenas parte das informações. Essa atitude parece ser a de maior consenso na literatura ${ }^{15}$.

A crença de que informar a criança faz parte da função do médico ganha força quando os sujeitos da presente pesquisa relataram que ao notificarem a criança eles tinham a sensação de dever cumprido.

O relato dos entrevistados, especialmente dos formados nos últimos anos, parece mostrar que esse tópico tem ocupado um espaço maior nos currículos médicos, sob a forma de discussões. No entanto, não se percebeu uma preocupação em criar condições de aprendizagem facilitadoras.
Artigos recentes dão conta de que, na graduação, há uma ênfase deficitária e inadequada nos aspectos psicológicos e uma ignorância da problemática da morte, assim como do preparo para lidar com outras situações difíceis ${ }^{17}$. Segundo Quintana, Cecin e Henn ${ }^{1}$, isto não seria um mero acaso. Por trás do descaso para com o tema haveria a intenção de preparar o aluno para lidar com essa problemática por meio do mecanismo de negação. A negação da vulnerabilidade pessoal e emocional do aluno seria incentivada pela escola médica. $\mathrm{O}$ sofrimento frente à doença seria visto como covardia ou fraqueza, havendo uma necessidade de demonstrar resistência emocional diante do grupo e escárnio frente à morte para provar que foi talhado para a profissão ${ }^{18}$. Segundo Zaidhaft ${ }^{19}$, são muito freqüentes as frases: "não se envolva com o paciente", "para aprender é assim mesmo", "se você fica sofrendo a cada paciente que morre, você não agüenta e larga a medicina". Para o autor, por trás da ideologia do não envolvimento está uma tentativa de afastar o médico da sua própria finitude, da de seus entes queridos e dos limites da própria medicina frente à vida.

A conseqüência disso é que, em muitos casos, mesmo sabendo da importância de colocar o paciente a par de seus problemas, o médico formado resiste em informar o diagnóstico de forma explicita, não respondendo às perguntas. Outras vezes, de forma implícita, recorre a termos técnicos que mais ocultam do que transmitem informações. Freqüentemente, o desejo de manter o paciente na ignorância é compartilhado pela família, e se estabelece um acordo tácito que impõe que a pessoa morra sem saber que vai morrer, mesmo que seu corpo esteja emitindo sinais de deterioração e que o tratamento esteja se tornando mais agressivo, sem resultados palpáveis.

Com a mudança dos atuais currículos, que incentivam o contato direto com o paciente desde o início do curso, as angústias de vivenciar a ambigüidade entre o desejo de salvar o paciente e os limites, sejam eles técnicos, sociais ou pessoais, ocorrem com os alunos bem precocemente. Percebe-se que há necessidade de retaguarda psicológica para que o aluno possa 
enfrentar essa nova realidade, o que nem sempre tem sido incorporado, efetivamente, nos currículos oficiais.

Nesta pesquisa, uma minoria dos sujeitos referiu ter sido capacitado para dar más notícias, no ensino regular. Segundo Premi ${ }^{2}$, é provável que os profissionais continuem se instrumentando a partir da auto-aprendizagem ou copiando professores mais graduados, como relataram alguns dos sujeitos mais velhos da pesquisa. Mas a oportunidade de aprendizagem a partir da observação do modelo vem se tornando cada vez mais rara com o número crescente de alunos por turma e a pulverização da responsabilidade pelo paciente.

Premi ${ }^{2}$, baseado na experiência geral e em conhecimentos convencionais, propõe algumas estratégias para a comunicação de más noticias, como dar ao paciente o controle sobre a quantidade e distribuição temporal das informações, minimizar a má noticia com uma boa notícia, nunca mentir, etc. Mas, como o próprio autor reconhece, não há regras de ouro, e às vezes é bastante difícil diferenciar o quanto o paciente quer saber, como reagirá e o sofrimento que essas informações trazem para o próprio profissional.

Em se tratando especificamente de crianças, os alunos precisariam ter noções básicas do desenvolvimento cognitivo, para entender como crianças de determinada idade compreendem o processo saúde-doença e morte, assim como a melhor maneira de fornecer-lhes informações. Por exemplo, utilizar comparações e metáforas para crianças menores, na faixa de quatro a seis anos, explicar os procedimentos atendo-se aos aspectos externos (o corte, a sedação, a sala de cirurgia) e deixar as explicações anatômicas para adolescentes que tiverem alcançado o estágio lógico-formal, por volta dos 12 anos de idade $^{20,21}$.

Ao lado dessas informações científicas, propõe-se a inclusão formal de vivências durante a graduação que recorram a outras estratégias de ensino, como, por exemplo, o emprego de técnicas psicodramáticas. Já há trabalhos nessa linha, mas são experiências esporádicas, sem a força transformadora necessária para aliviar a ansiedade e humanizar o ensino ${ }^{22}$.

Os jogos dramáticos e o sociodrama possibilitariam abordar a polêmica moral e ética envolvida na tomada de decisão sobre informar ou não à criança. Pesquisadores que analisaram relatos de alunos de graduação do curso médico verificaram que, apesar da visão organicista vigente na maioria das faculdades, eles têm a percepção de que várias decisões na sua ação profissional não são pautadas apenas pela objetividade, mas influenciadas pela subjetividade, tanto deles quanto do paciente. Segundo Ramos-Cerqueira et al..$^{22}$, as situações trazidas por esses alunos em dramatizações explicitam a ansiedade que essa descoberta provoca e, paralelamente, o alívio de ver que essas sensações são compartilhadas com os outros alunos e com a comunidade médica de forma mais ampla.

As grandes polêmicas atuais - e, certamente, lidar com a morte é uma delas - não serão solucionadas no âmbito restrito do ensino médico, mas nele têm que ser debatidas. $\mathrm{O}$ relato dos médicos entrevistados, dando conta de que esse assunto foi abordado durante a formação, é um sinal positivo, mas a ausência de capacitação mais específica precisa ser levada em conta. Estar convencido de que o paciente tem direito à informação não garante que ela seja transmitida se a situação for avaliada como muito difícil. Nesse sentido, as atividades de role-playing, utilizadas como recurso didático em vários cursos de Psicologia Médica, poderiam capacitar o aluno a desempenhar o papel de comunicador em uma situação protegida, recebendo feedbacks do grupo sobre seu desempenho e sugestões ${ }^{23}$.

No contexto médico, a comunicação de más notícias é um processo estressante tanto para o paciente quanto para o médico. Estudos mostram que, antes de informar o paciente, o médico vive um estresse antecipatório, medo e ansiedade. Os estudantes de Medicina relatam, ainda, incerteza em como lidar com as reações do paciente ${ }^{24}$. Os treinamentos pré-programados durante o curso poderão diminuir a sensação de desconforto ${ }^{4} \mathrm{e}$ ajudar o aluno e o médico a encontrar formas de enfrentamento para lidar com o estresse que essa situação provoca, reduzindo a ansiedade e tornando a comunicação mais efetiva.

\section{REFERÊNCIAS}

1. Quintana MA, Cecim OS, Henn CG. O preparo para lidar com a morte na formação do profissional de Medicina. Rev. Bras. Educ. Méd. 2002; 26 (3): 204-210.

2. Premi, JN. Communicating Bad News. World Health Organization. Genebra, 1993.

3. Oken D. What to tell cancer patients. Journal of American Medical Association.1961; 175: 1120-1126.

4. Greenberg LW, Ochsenchlager D, O'Donnell R, Mastruserio L, Cohen GJ. Communicating bad news: a pediatric department's evaluation of a simulated intervention. Pediatrics. 1999; 103 (6): 1210-1217.

5. Krahn GL, Hallum A, Kime C. Are there good ways to give bad news? Pediatrics. 1993; 91: 578-582.

6. Hart C, Chesson R. Children as consumers. British Medical Journal. 1998; 316: 1600-1603.

7. Brewster A. Chronically ill hospitalized children's concepts of their illness. Pediatrics. 1982; 69: 355-362.

8. Perrin EC, Sayer A, Willet J. Sticks and stones may break my bone... Reasoning about illness causality and body functioning in children who have a chronic illness. Pediatrics. 1991; 88, 604-619. 
9. Hansdottir J, Malcarne V. Concepts of illness in Icelandic Children. Journal of Pediatric Psychology.1998; 23: 187195.

10. Pantell RH, Stewart TJ, Dias J, Wells P, Ross W. Physician communication with children and parents. Pediatrics. 1982; 70 (3): 396-402.

11. Tates K, Meeuwesen L, Elbers E, Bensing J. I've come for his throat: roles and identities in doctor-parent-child communication. Child: Care Health and Development. 2001; 28 (1): 109-116.

12. Nitschke R, Humphrey GB, Sexauer CL, Catron B, Wunder $\mathrm{S}$, Jay $\mathrm{S}$. Therapeutic choices made by patients with endstage cancer. Journal of Pediatrics. 1983; 101 (1): 471-476.

13. Leikin SL, Connell. Editorial correspondence: therapeutic choice by children with cancer. The Journal of Pediatrics. 1983; 103 (1): 167.

14. Shumway CN, Grossman L, Sarles LM. Editorial correspondence: therapeutic choice by children with cancer. The Journal of Pediatrics. 1983; 103 (1): 168.

15. Hilden JM, Walterson J, Chrastek J. Tell the Children. Journal of Clinical Oncology. 2000; 18: 3193-3195.

16. Bardin L. Análise de Conteúdo. Lisboa: Edições 70, 1977.

17. Castro FC. Os temores na formação e pratica da Medicina. Rev. Bras. Educ. Méd. 2004; 28 (1): 38-45.

18. Grosseman S, Patrício ZM. Do desejo à realidade de ser médico. Florianópolis: Editora da UFSC, 2004.

19. Zaidhaft S. Morte e formação médica. Rio de Janeiro: Franciaco Alves, 1990.
20. Bibace R, Walsh M. Development of children's concepts of illness. Pediatrics. 1980; 66 (6): 912-917.

21. Whitt JK, Dykstra D, Taylor CA. Children's conceptions of illness and cognitive development. Clinic.Pediatrics. 1979; 18: 307-339.

22. Ramos-Cerqueira AT, Lima MCP, Torres AR, Reis JRT, Fonseca NMV. Era uma vez... contos de fada e psicanálise auxiliando alunos na conclusão do curso médico. Interfacecomunicação, saúde e educação. 2005; 9 (16): 81-89.

23. Soeiro AC. Psicodrama e psicoterapia. São Paulo: Natura, 1976.

24. Ptacek JT, Eberhardt TL. Breaking bad news: a review of literature. JAMA. 1996; 276 (6): 496-502.

ANEXO: O questionário utilizado está disponível para consulta em http:/ / www.educacaomedica.org.br/Anexos

\section{CONFLITOS DE INTERESSE}

Declarou não haver.

\section{ENDEREÇO PARA CORRESPONDÊNCIA}

Gimol Benzaquen Perosa

Departamento de Neurologia e Psiquiatria

Rubião Júnior, s/n - Botucatu

CEP 18618-970 / SP

E-mail: gimol@fmb.unesp.br 